\title{
Transplantation of DBA/2 Mouse Corneas in BALB/c Recipients Signifi- cantly Delays Graft Rejection Compared with C3H Grafts and Facilitates Studies on Gene Transfer
}

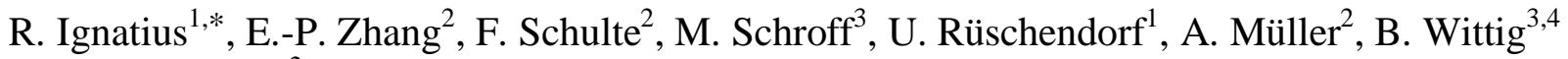 \\ and F. Hoffmann ${ }^{2}$
}

\begin{abstract}
${ }^{I}$ Institute of Microbiology and Hygiene, Department of Infection Immunology, Charité - Universitätsmedizin Berlin, Campus Benjamin Franklin, Hindenburgdamm 27, 12203 Berlin; ${ }^{2}$ Department of Ophthalmology, Charité - Universitätsmedizin Berlin, Campus Benjamin Franklin, Hindenburgdamm 30, 12200 Berlin; ${ }^{3}$ Mologen AG, 14180 Berlin, Germany and ${ }^{4}$ Charité, Department of Molecular Biology and Bioinformatics, Arnimallee 22, 14195 Berlin Germany
\end{abstract}

\begin{abstract}
To study the impact of gene transfer in experimental corneal transplantation, grafts should reliably be rejected but after a time span, which allows multiple interventions. We were interested in delaying transplant survival time through MHC-matching of donor and recipient animals and in omitting local dexamethasone treatment, which is laborious and could potentially interfere with the expression of administered DNA. Rejection of DBA/2 (H-2d) corneas by BALB/c (H$2 \mathrm{~d})$ recipients occurred significantly delayed compared with $\mathrm{C} 3 \mathrm{H}(\mathrm{H}-2 \mathrm{k})$ grafts $(25.0 \pm 5.6$ vs. $14.5 \pm 4.1$ days, $\mathrm{p}=0.038)$, and correlated with the expression of allospecific T cell-proliferation and IFN- $\gamma$ secretion in draining lymph nodes. Gene gun treatment with IL-4/CTLA-4 DNA MIDGE ${ }^{\mathrm{TM}}$ vectors in the lower lid of recipients significantly prolonged survival of $\mathrm{DBA} / 2$ corneas in BALB/c mice. This refined and dexamethasone-free protocol may be advantageous for the development of novel treatment strategies, e.g., local gene transfer, in corneal transplantation.
\end{abstract}

\section{INTRODUCTION}

Gene therapy holds great promise for various corneal disorders including allograft rejection. Three different technical approaches have been shown to be feasible, i.e., treatment of the corneal epithelium, the stroma, or the endothelium. While both stroma and endothelium can be manipulated only before or during the procedure of transplantation, repeated treatments of the epithelium are feasible following keratoplasty. We previously showed prolonged survival of murine corneal grafts following transfer of cytokine DNA by gene gun treatment to the cornea [1] and also to the lower lid [2]. Regarding the way of gene delivery we opted for small gene vectors in order to keep vector-induced inflammatory reactions to a minimum.

One standard mouse model for studying corneal allograft survival has been established by embedding grafts from $\mathrm{C} 57 \mathrm{Bl} / 6$ mice into the eyes of BALB/c recipients [3]. While this model allows studies aimed at understanding the immunological mechanisms underlying graft rejection, it is not optimal for studying the impact of gene therapy on the process of rejection, since - although MHC-mismatched mouse strains are used - less than $50 \%$ of the grafts are rejected. A mouse model with a rejection rate of $100 \%$, however, is required for a comprehensive evaluation of strategies that intend to prolong survival or interfere with rejection. In our

*Address correspondence to this author at the Institute of Microbiology and Hygiene, Department of Infection Immunology, Charité - Universitätsmedizin Berlin, Campus Benjamin Franklin, Hindenburgdamm 27, 12203 Berlin, Germany; E-mail: ralf.ignatius@charite.de previous experimental model $(\mathrm{C} 3 \mathrm{H}$-donors and BALBcrecipients) acute rejection of the grafts generally occurs within around two weeks in $100 \%$ of the recipients [4]. To prolong the time between transplantation and rejection, treatment with dexamethasone eye drops is mandatory. However, multiple daily applications of eye drops to mice are laborious and corticosteroids could potentially interfere with the expression of peri-operatively administered cytokine DNA.

Although minor histocompatibility antigens may be more important for corneal graft rejection than MHC molecules [5, 6], we tested whether the use of MHC-identical mouse strains, which only display different minor histocompatibility antigens, may provide an experimental model that is better suited for gene transfer strategies. Here we show that the use of DBA/2 donor and $\mathrm{BALB} / \mathrm{c}$ recipient mice further delays graft rejection and thereby provides additional time that can be used to interfere with the induction of allospecific immune responses.

\section{MATERIALS AND METHODS}

\section{Animals}

Three-month-old female mice weighing 20 to $25 \mathrm{~g}$ were obtained from the Bomholtgård Breeding and Research Center (Denmark). Corneal grafts from $3 \mathrm{C} 3 \mathrm{H}(\mathrm{H}-2 \mathrm{k})$ or 15 DBA/2 (H-2d) mice were transplanted in $36 \mathrm{BALB} / \mathrm{c}(\mathrm{H}-2 \mathrm{~d})$ mice. All animals were treated according to the "Principles of Laboratory Animal Care" (NIH publication Vol. 25, No. 28 , revised in 1996). Two additional C3H and $2 \mathrm{DBA} / 2$ mice 
were sacrificed without prior treatment and the corneas were removed for immunohistochemical analyses.

\section{Orthotopic Corneal Transplantation and Post-Operative Treatment}

As the numbers of APCs per graft could potentially influence the time between transplantation and rejection, sections of the corneal stroma obtained from both mouse strains were analyzed immunohistologically regarding myeloid cells of the macrophage/dendritic cell lineage, which stain positive for F4/80 and MHC class II molecules [7]. Corneas from both mouse strains showed a similar distribution and contained comparable numbers of $\mathrm{F} 4 / 80^{+}$cells $(\mathrm{C} 3 \mathrm{H}: 29.8 \pm 6.1$ cells/section; DBA/2: $20.3 \pm 5.1$ cells/section; $\mathrm{p}=0.06)$.

Procedures of corneal transplantation and anesthesia have previously been described [8,9]. Two and seven days after transplantation sutures were removed from the lids and corneas, and all animals were examined at the slit-lamp. Subsequently, transparency of corneal grafts was assessed every one to two days as edema and/or clouding and rated on a scale of 0 to 5 points [3], an allograft reaction being diagnosed with $>2$ points.

\section{Immunohistochemistry}

Tangential sections from frozen flattened corneas from 2 untreated $\mathrm{C} 3 \mathrm{H}$ and $2 \mathrm{DBA} / 2$ mice were cut from the most superficial subepithelial corneal layer [7], and $\mathrm{F} 4 / 80^{+}$cells were stained with a rat anti-mouse F4/80 monoclonal antibody (mAb) (Clone Cl:A3-1, Dako, Hamburg, Germany) followed by a biotinylated mouse anti-rat mAb (Pharmingen, Heidelberg, Germany). The reaction was visualised using an avidin-biotin-complex alkaline phosphatase kit (Vectastain ${ }^{\circledR}$, Alexis Corp., Grünberg, Germany). Data are given as mean numbers of cells per section $+/-\mathrm{SD}$.

\section{Allospecific Immune Responses}

Non-specific inflammation can limit corneal transplant survival, and we previously used dexamethasone locally to avoid non-specific inflammatory responses. To ensure that the grafts in the present model in the absence of steroids were rejected due to the expression of $\mathrm{T}$ cell-mediated immune responses, we determined the presence of allospecific $\mathrm{T}$ lymphocytes in the draining lymphoid tissue.

$7.5 \times 10^{5}$ pooled cells from the ipsilateral or contralateral submandibular lymph nodes of recipient mice were incubated with $7.5 \times 10^{5}$ irradiated spleen cells in triplicates in RPMI 1640 (GIBCO, Invitrogen, Karlsruhe, Germany), supplemented with $2 \mathrm{mM}$ L-glutamine (GIBCO), $50 \mu \mathrm{M} 2$ mercaptoethanol (Sigma, Deisenhofen, Germany), $10 \mathrm{mM}$ HEPES (GIBCO), penicillin (100 U/ml)-streptomycin (100 $\mu \mathrm{g} / \mathrm{ml}$ ) (GIBCO), and $10 \%$ heat-inactivated fetal calf serum (Biochrom, Berlin, Germany) in 96-well round bottom trays (Nunc, Roskilde, Denmark) at $37^{\circ} \mathrm{C}$ and $5 \% \mathrm{CO}_{2}$. On day 3 , supernatants were harvested and stored at $-70^{\circ} \mathrm{C}$ for analysis of interferon (IFN)- $\gamma$ secretion. As controls, lymph node cells were stimulated by Concanavalin A (Con A, $5 \mu \mathrm{g} / \mathrm{ml}$, Sigma, Deisenhofen, Germany) or incubated in the presence of medium alone. Tritiated thymidine ( $1 \mu \mathrm{Ci} /$ well, NEN, Köln, Germany) was added to the wells, and ${ }^{3} \mathrm{H}$-thymidine incorporation was measured as cpm after another $18 \mathrm{~h}$ of incuba- tion. Successful irradiation was confirmed by incubation of spleen cells in the presence of ConA, and proliferation of these cultures never exceeded $2000 \mathrm{cpm}$. IFN- $\gamma$ concentrations in cell culture supernatants were determined using a commercially available ELISA (BD Biosciences, San Diego, USA).

\section{Gene Therapy}

Minimalistic, immunologically-defined, gene expression $\left(\mathrm{MIDGE}^{\mathrm{TM}}\right.$ ) constructs were provided by Mologen (Berlin, Germany) and were synthesized as described before [1]. Vectors were administered with the Helios Gene Gun ${ }^{\circledR}$ delivery system (Bio-Rad Laboratories, München, Germany) using $1 \mathrm{mg}$ of $1.6-\mu \mathrm{m}$ gold powder (ABCR, Karlsruhe, Germany) loaded with $1 \mu \mathrm{g}$ of MIDGE DNA and using a helium pressure setting of 250 psi. Cartridges containing gold particles coated with MIDGETM constructs were prepared according to the manufacturer's instructions. The skin of the left lower lids or of the left shanks was treated three times within one minute at the time of transplantation and on days 2 and 7 after keratoplasty (total DNA load: $9 \mu \mathrm{g}$ ).

\section{Statistics} U test.

Data were statistically analyzed using the Mann-Whitney

\section{RESULTS}

\section{Prolonged Survival of DBA/2 Compared to C3H Grafts in BALB/c Recipients}

Two groups of six BALB/c mice each received corneal grafts from either $\mathrm{C} 3 \mathrm{H}$ or $\mathrm{DBA} / 2$ mice. Despite local antibiotic treatment, two eyes (transplanted with grafts from the same donor animal) got postoperatively infected, and the recipients were excluded from the study. All other grafts were clear when the lids were opened. Allograft rejection occurred on day $14.5 \pm 4.1$ (mean $\pm \mathrm{SD}$ ) when $\mathrm{C} 3 \mathrm{H}$ donors were used and on day $25.0 \pm 5.6$ with grafts from DBA/2 donors $(\mathrm{p}=0.038$, Fig. 1).

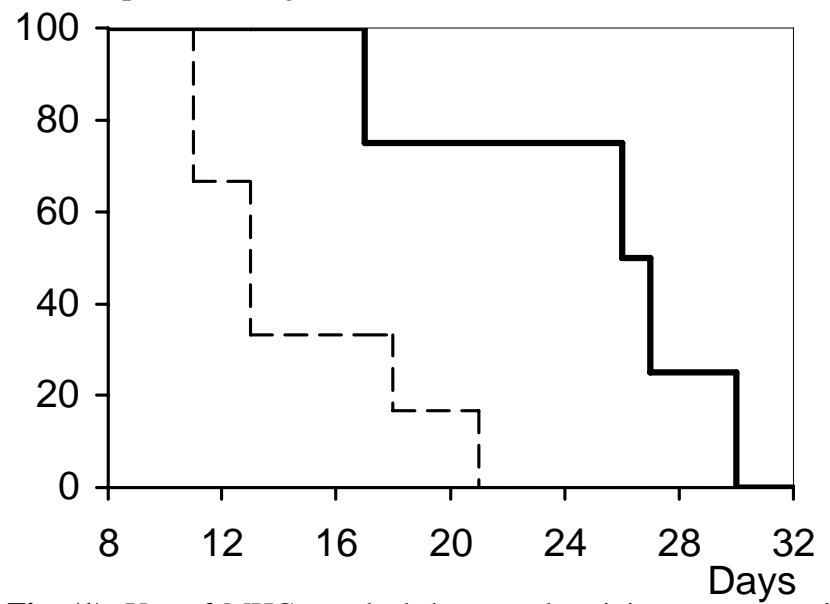

Fig. (1). Use of MHC-matched donor and recipient mouse strains significantly prolongs corneal graft survival. BALB/c mice received corneal grafts from either $\mathrm{C} 3 \mathrm{H}$ (dotted line) or $\mathrm{DBA} / 2$ mice (bold line). Cumulative survival of allografts is shown $(\mathrm{p}=0.038)$.

T-cell proliferative responses were detected one to two days after the onset of rejection in draining lymph nodes following transplantation of $\mathrm{C} 3 \mathrm{H}$ or $\mathrm{DBA} / 2$ donor corneas 
(Table 1), and these $\mathrm{T}$ cells secreted substantial amounts of IFN- $\gamma$ (Table 2). These Th1 immune responses of BALB/c recipients did not differ considerably after transplantation of $\mathrm{C} 3 \mathrm{H}$ or $\mathrm{DBA} / 2$ corneas. Thus, transplantation of $\mathrm{DBA} / 2$ corneas into $\mathrm{BALB} / \mathrm{c}$ mice leads to a longer graft survival than transplantation of $\mathrm{C} 3 \mathrm{H}$ corneas and graft rejection is due to the expression of allospecific immune responses. Importantly, still all grafts are rejected, which is favourable for studies that intend to interfere with graft rejection.

Table 1. Alloreactive T-Cell Proliferation in Lymph Node Cells from BALB/c Mice at the Time of Rejection of Corneal Grafts from C3H or DBA/2 Mice

\begin{tabular}{|c|c|c|c|c|}
\hline \multirow{2}{*}{$\begin{array}{c}\text { Donor } \\
\text { Mouse Strain }\end{array}$} & \multirow{2}{*}{$\begin{array}{c}\text { Site of } \\
\text { Lymph Nodes }\end{array}$} & \multicolumn{3}{|c|}{ Stimuli } \\
\cline { 3 - 5 } & & Spleen Cells* & Medium & ConA \\
\hline \hline \multirow{2}{*}{ C3H } & ipsilateral & 31,996 & 8,540 & 291,461 \\
\cline { 3 - 5 } & contralateral & 8,789 & 3,696 & 276,732 \\
\hline \multirow{2}{*}{ DBA/2 } & ipsilateral & 73,698 & 7,625 & 290,304 \\
\cline { 3 - 5 } & contralateral & 17,115 & 8,747 & 194,279 \\
\hline
\end{tabular}

* Lymph node cells were stimulated by irradiated donor spleen cells, ConA $(5 \mu \mathrm{g} / \mathrm{ml})$ as a positive control, or incubated in the presence of medium alone (negative control). Proliferation was measured as cpm on day 3 , results of irradiated spleen cells incubated in the presence of ConA never exceeded $2000 \mathrm{cpm}$.

Table 2. IFN- $\gamma$ Secretion $(\mathrm{ng} / \mathrm{ml})$ by Submandibular Lymph Node Cells from BALB/c Mice at the Time of Rejection of Corneal Grafts from C3H or DBA/2 Mice

\begin{tabular}{|c|c|c|c|c|}
\hline \multirow{2}{*}{$\begin{array}{c}\text { Donor } \\
\text { Mouse Strain }\end{array}$} & \multirow{2}{*}{$\begin{array}{c}\text { Site of } \\
\text { Lymph Nodes }\end{array}$} & \multicolumn{3}{|c|}{ Stimuli } \\
\cline { 3 - 5 } & & Spleen Cells* & Medium & ConA \\
\hline \hline \multirow{2}{*}{$\mathrm{C} 3 \mathrm{H}$} & ipsilateral & 19.10 & $<0.36$ & 62.26 \\
\cline { 3 - 5 } & contralateral & 0.66 & $<0.36$ & 59.19 \\
\hline \multirow{2}{*}{ DBA/2 } & ipsilateral & 14.00 & $<0.36$ & 65.19 \\
\cline { 2 - 5 } & contralateral & $<0.36$ & $<0.36$ & 56.34 \\
\hline
\end{tabular}

* Lymph node cells were stimulated by irradiated donor spleen cells, ConA ( $5 \mu \mathrm{g} / \mathrm{ml})$ as a positive control, or incubated in the presence of medium alone (negative control). Supernatants were harvested after 3 days.

\section{Successful Gene Therapy Further Extends Survival Time of DBA/2 Grafts in BALB/c Recipients}

We have previously shown that ballistic gene transfer of CTLA-4 and IL-4 DNA into the lower lid significantly prolongs the survival time of the grafts whereas transfer of empty control vectors did not affect transplant survival [2]. To confirm that the present model still allows experimental gene transfer strategies, we treated two groups of BALB/c recipients of DBA/2 corneas $(n=8$ each) through ballistic gene transfer of CTLA-4 and IL-4 DNA into the skin of the lower lid or the shank, however, less frequently than in our previous studies. Eight additional recipients remained untreated. Postoperatively, one lid-treated and one untreated animal were excluded because of infection while all other grafts were clear when the lids were opened. Allograft rejection occurred in six of the seven remaining control animals, in seven of the eight shank-treated, and in three of the seven lid-treated animals (Fig. 2). The remaining six grafts (one in the controls, one in the shank-treated, and four in the lidtreated animals) remained clear until day $33(\mathrm{p}=0.026$ lidtreated vs. untreated, $\mathrm{p}=0.040$ lid-treated vs. shank-treated). Therefore, grafting of DBA/2 corneas into BALB/c recipients allows gene therapy and provides a longer time span for the performance of therapeutic strategies intending to interfere with graft rejection than our previously established model.

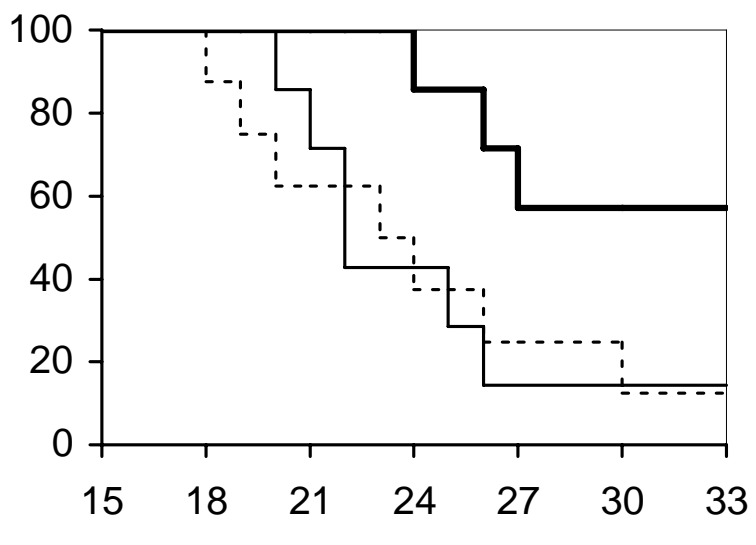

Days

Fig. (2). CTLA-4/IL-4 DNA treatment of the lower lid significantly prolongs corneal graft survival in MHC-matched mice. BALB/c mice were treated on days 0,2 , and 7 after transfer of DBA/2 corneas with vector CTLA-4 and IL-4 DNA (total DNA load: 9 $\mu \mathrm{g} /$ animal) through ballistic gene transfer into the skin of the lower lid ( $\mathrm{n}=8$, bold line) or into the skin of the shank ( $\mathrm{n}=8$, dotted line). 8 animals remained untreated $(n=8$, thin line). Cumulative survival of allografts is shown ( $\mathrm{p}=0.026$ lid-treatment $v$ s. untreated, $\mathrm{p}=0.040$ lid-treatment $v s$. shank-treatment).

\section{DISCUSSION}

The present study aimed at establishing a murine model of keratoplasty with - in the absence of local corticosteroid treatment - a delayed (longer than 14 days) but reliable rejection of all grafts to set stage for future studies of gene transfer. Although there is ample evidence that minor histocompatibility antigens play an important role in corneal graft rejection $[5,6]$ the present study demonstrates that the use of the MHC-matched DBA/2 and BALB/c mouse strains leads to a significantly delayed rejection of the grafts compared with $\mathrm{MHC}$-mismatched $\mathrm{C} 3 \mathrm{H}$ donors. Nevertheless, we cannot exclude that the longer survival of the grafts in our model is due to a favorable match regarding minor histocompatibility antigens.

A benefit of MHC-matching in murine corneal transplantation has also been reported by Yamada et al. [10] who demonstrated differences in corneal allograft survival depending on whether they placed MHC-matched and MHCmismatched grafts in high-risk graft beds. The modulation of the intracellular thiol status of macrophages (and possibly also of other antigen-presenting cells, such as dendritic cells) in $\mathrm{BALB} / \mathrm{c}$ recipients prior to transplantation led to a pro- 
longed survival of MHC-matched but minor histocompatibility antigen incompatible grafts, e.g., B10.D2 and also DBA/2 grafts as in our experiments. In contrast, there was no suppressive effect by the induction of oxidative antigenpresenting cells on the rejection of grafts from MHCmismatched mouse strains $(\mathrm{C} 57 \mathrm{~B} 1 / 10$ grafts in $\mathrm{BALB} / \mathrm{c}$ recipients). Likewise, MHC-matching reduces the risk of corneal graft rejection when IFN- $\gamma$ secretion is depressed or absent [11].

This new model is less laborious and importantly, more adapted to the performance of gene therapy studies than our previous model [1, 2]. Daily dexamethasone eye drops, which could potentially interfere with the expression of the DNA brought in through gene transfer, are dispensable for the achievement of a graft survival time longer than 14 days. In addition, corneal sutures can be removed earlier after surgery than before. The modified experimental protocol allows repeated therapeutic interventions, as shown by the results of our gene transfer experiment - ballistic gene transfer may even be more effective under these conditions -, and future studies in this model may concentrate on influencing the allograft rejection by using genes of various cytokines at several treatment times. In conclusion, the model of transplantation of DBA/2 corneal grafts into BALB/c recipients provides an improved animal model for investigating experimental methods aiming at the prolongation of graft survival, particularly for studies of gene transfer to the cornea or the lower lid.

\section{CONFLICT OF INTEREST}

MS and BW are affiliated with MOLOGEN AG, Berlin, Germany, and hold publicly traded shares of the company (ISIN DE0006637200). RI, E-PZ, FS, UR, AM, and FH declare no conflicts of interests.

\section{ACKNOWLEDGEMENT}

We thank the Deutsche Forschungsgemeinschaft (Ho 674/9-3 to FH) for financial support.

\section{REFERENCES}

[1] Konig Merediz SA, Zhang EP, Wittig B, et al. Ballistic transfer of minimalistic immunologically defined expression constructs for IL4 and CTLA4 into the corneal epithelium in mice after orthotopic corneal allograft transplantation. Graefes Arch Clin Exp Ophthalmol 2000; 238(8): 701-7.

[2] Zhang EP, Franke J, Schroff M, et al. Ballistic CTLA4 and IL-4 gene transfer into the lower lid prolongs orthotopic corneal graft survival in mice. Graefes Arch Clin Exp Ophthalmol 2003; 241 (11): 921-6.

[3] Sonoda Y, Streilein JW. Orthotopic corneal transplantation in mice--evidence that the immunogenetic rules of rejection do not apply. Transplantation 1992; 54(4): 694-704.

[4] Muller A, Zhang EP, Hoffmann F. Effect of topical dexamethasone treatment on antigen-presenting cells in murine corneas. Ophthalmologe 2003; 100(4): 310-3

[5] Streilein JW, Arancibia-Caracamo C, Osawa H. The role of minor histocompatibility alloantigens in penetrating keratoplasty. Dev Ophthalmol 2003; 36: 74-88.

[6] Osawa H, Streilein JW. MHC class I and II antigens as targets of rejection in penetrating keratoplasty in low- and high-risk mouse eyes. Cornea 2005; 24(3): 312-8.

[7] Muller A, Zhang EP, Schroff M, et al. Influence of ballistic gene transfer on antigen-presenting cells in murine corneas. Graefes Arch Clin Exp Ophthalmol 2002; 240(10): 851-9.

[8] Zhang EP, Schrunder S, Hoffmann F. Orthotopic corneal transplantation in the mouse--a new surgical technique with minimal endothelial cell loss. Graefes Arch Clin Exp Ophthalmol 1996; 234(11): 714-9.

[9] Zhang EP, Hoffmann F. Low-dose anesthesia for corneal transplantation in mice. Graefes Arch Clin Exp Ophthalmol 2005; 243(1): 72-5

[10] Yamada J, Maruyama K, Sano Y, et al. Promotion of corneal allograft survival by the induction of oxidative macrophages. Invest Ophthalmol Vis Sci 2004; 45(2): 448-54.

[11] Hargrave SL, Hay C, Mellon J, et al. Fate of MHC-matched corneal allografts in Th1-deficient hosts. Invest Ophthalmol Vis Sci 2004; 45(4): 1188-93. 